\begin{abstract}
Iranica
Abstracta Iranica Revue bibliographique pour le domaine irano-aryen

Volume 37-38-39 | 2018

Comptes rendus des publications de 2014-2016
\end{abstract}

\title{
Christelle Jullien (éd.). Husraw Ier. Reconstructions d'un règne. Sources et documents
}

Julien Cuny

\section{(2) OpenEdition \\ Journals}

Édition électronique

URL : http://journals.openedition.org/abstractairanica/47255

DOI : 10.4000/abstractairanica.47255

ISBN : 1961-960X

ISSN : 1961-960X

Éditeur :

CNRS (UMR 7528 Mondes iraniens et indiens), Éditions de l'IFRI

Référence électronique

Julien Cuny, « Christelle Jullien (éd.). Husraw ler. Reconstructions d'un règne. Sources et documents », Abstracta Iranica [En ligne], Volume 37-38-39 | 2018, document 79, mis en ligne le 30 décembre 2018, consulté le 27 septembre 2020. URL : http://journals.openedition.org/abstractairanica/47255 ; DOI : https://doi.org/10.4000/abstractairanica.47255

Ce document a été généré automatiquement le 27 septembre 2020

Tous droits réservés 


\title{
Christelle Jullien (éd.). Husraw Ier. Reconstructions d'un règne. Sources et documents
}

\author{
Julien Cuny
}

\section{RÉFÉRENCE}

Christelle Jullien (éd.). Husraw Ier. Reconstructions d'un règne. Sources et documents. Paris : Association pour l'Avancement des Études iraniennes, 2015, 341 p., ill., index. (Studia Iranica. Cahier 53)

1 Les treize contributions réunies dans cet ouvrage sont issues d'un colloque organisé à Paris en octobre 2014, dans l'objectif affiché et réussi, non d'offrir une vision synthétique du règne de Husraw $\mathrm{I}^{\mathrm{er}}$ (r. 531-579), mais de croiser les regards issus de l'analyse de corpus documentaires caractérisés par leur diversité de nature et de contenus, qui justifie le pluriel du titre: il s'agit en effet de "reconstructions» différentes $\mathrm{du}$ règne $\mathrm{du}$ plus célèbre des rois sassanides, plutôt que d'une " reconstruction " globale, qui n'émerge pas aisément de cet ensemble kaléidoscopique. Les communications sont en général autant d'utiles synthèses de données que des déconstructions critiques permettant d'évaluer leurs valeurs informatives. Certains articles sont quelquefois la relecture d'une source apportant un éclairage nouveau sur une question particulière. La diversité des domaines abordés, mal masquée par la répartition des communications en quatre thèmes dont on a parfois du mal à comprendre la logique, reflètent cette diversité des documents disponibles. Mais la permanence de thèmes récurrents comme les relations romano-perses ou la question du mouvement mazdakite, certes très importants, témoigne aussi de la difficulté à renouveler les questionnements face à des corpus documentaires qui ne sont pas ou peu en expansion. On trouvera donc peu de données nouvelles ou inédites au sens strict. 
2 Les contributions d'Andrea Gariboldi et de Michael Richard Jackson Bonner permettent de replacer l'ensemble des débats historiographiques sur le règne de Husraw Ir, longtemps fondés exclusivement sur les textes des historiens d'époque islamique, et d'en poser clairement les limites. La révolte mazdakite et les réformes du roi en sont des thèmes centraux, encore sujet à des interprétations diverses. En ce qui concerne le mouvement mazdakite, Jackson Bonner tend à le réduire à une réalité moins catastrophique que ce que la tradition islamique en a transmis. Aussi les contributions de François de Blois et de Maria Macuch s'avèrent-elles particulièrement intéressantes. Le premier apporte de nouveaux arguments (notamment une date pour Mazdak fils de Bāmdād chez Birūnī) à l'appui de la reconstitution des évènements proposée en 1991 par P. Crone. Mazdak, dont le nom correspond à plusieurs personnages, pourrait n'avoir été qu'un titre attribué au leader d'une communauté religieuse qui aurait existé dès le $\mathrm{III}^{\mathrm{e}} \mathrm{s}$. apr. et que l'A. propose de reconnaître dans un terme jusque-là jamais correctement interprété des inscriptions de Kirdīr. Le mazdakisme serait un mouvement proche de la mouvance manichéenne et au sein duquel, contrairement à une idée reçue, ascétisme et jeûne auraient été valorisés. La contribution de M. Macuch, par l'analyse très précise de termes juridiques, montre au plus près de la réalité sociale tout ce que les pratiques mazdakites ont pu avoir de subversif.

3 À partir du temps long des données archéologiques, Rémy Boucharlat replace judicieusement le règne de Husraw $\mathrm{I}^{\mathrm{er}}$ dans la durée d'un «long VI ${ }^{\mathrm{e}}$ siècle ", voire dans le cadre plus large encore de l'ensemble de l'époque sassanide. De cette revue des données ressort, de l'aveu même de l'A., une certaine déception devant l'étendue des zones d'ombre que connait encore l'archéologie de cette période. Pour certaines régions mal connues comme le Sistan, ces lacunes sont partiellement comblées par les données sigillographiques et numismatiques, ici croisées de façon originale avec les informations fournies par les textes chrétiens et juifs pour reconstruire une trame politique et administrative (Rika Gyselen et Christelle Jullien). L'étude de la production des ateliers monétaires de l'ensemble de l'empire sous Husraw I $^{\text {er }}$ (Nikolaus Schindel) permet une approche régionale comparée en démontrant par exemple le poids plus important de régions comme le Hūzestān par rapport aux ateliers de la capitale. L'importante continuité de la répartition de ses ateliers depuis Pērōz jusqu'à Husraw I ${ }^{\text {er }}$ prouve également que l'administration monétaire n'a pas subi l'impact de la révolte mazdakite, ce qui tendrait à en minimiser l'importance. L'utilité des textes chrétiens syriaques pour la connaissance d'aspects très précis des pratiques ou de l'organisation religieuse de l'Église mazdéenne est encore démontrée par Florence Jullien pour l'époque de Husraw I ${ }^{\mathrm{er}}$. L'analyse de Samra Azarnouche de la littérature moyen-perse conclut que celle-ci doit être abordée avec prudence car s'y déploie une image parfaitement idéalisée, et donc déformée, de ce roi et ce son action.

4 L'apport des sources arméniennes et byzantines est également évalué dans deux contributions (Giusto Traina, Philip Huyse). Le premier A. rappelle la nécessité de les confronter pour les décrypter et prend l'exemple de la persistance des prétentions de la dynastie arsacide après leur éviction en 428 , dont les textes arméniens ne rendent pas compte. P. Huyse passe en revue les principaux auteurs byzantins: bien que tous baignent dans l'image du barbare perse, ils livrent aussi des informations précieuses et ne sauraient donc être écartés. Enfin les études de Didier Marcotte et Michel Tardieu fond le point sur la présence dans l'empire sassanide des derniers représentants de 
l'école philosophique d'Athènes chassés par Justinien en 531, et analysent ce qu'on peut retenir de la réalité de l'évènement et de son contexte.

\section{AUTEURS}

\section{JULIEN CUNY}

Conservateur au Musée du Louvre, Paris 